\title{
CORRELATO
}

\section{CONDUCTA DEL UROLOGO-PEDIATRA FRENTE A LA PIELONEFRITIS}

\author{
DrS. FELIX CANTIN, ANTONIO MOREY y MOISES RIVEROS \\ Servicio de Urologia Hospitat "Luis Calvo Mackenna". Santiago.
}

El presente correlato al tema de "Pielonefritis en la Infancia" es parte de nuestra experiencia de más o menos una década de trabajo en el esclarecimiento de los problemas urológicos del niño y muy especialmente, en este de la infección urinaria, cuya importancia, si bien ha disminuído con el advenimiento de los antibióticos, no la ha perdido como motjvo de consulta, siendo así como debemos esclarecer en las piurias crónicas, aspectos del germen causal, del foco de origen o de las condiciones anatómicas locales que está influenciando su mante. nimiento.

Por su carácter de contribución al tema, o correlato, nuestro trabajo se refiere a caracteres particularísimos o unilaterales de este tema que en los últimos decenios ha sido objeto de variadas discusiones, tanto sobre su etiopatogenia, anatomía patológica y especialmente, la terminología que debe emplearse en su denominación; mucho de esto a raíz de los trabajos de Longcope en 1937 y Weiss y Parker en 1939, quienes con sus publicaciones elevaron a la pielonefritis al rango de una enfermedad preponderante en la producción de uremia crónica, del riñón retraído y de la enfermedad hipertensiva.

En nuestro propósito hemos tenido en cuenta los conceptos de Bell, Bertrand F'cntaine, Couvelaire, Oberling, Jimènez Díaz y muy especialmente, a Campbell en cuyas lecciones se clarifican y determinan todas las circunstancias en que el urólogo debe estar íntimamente ligado al clínico en el estudio, control y tratamiento de esta nosología. Fué, pues, nuestra intención desde un comienzo, concientes del escaso tiempo a disponer para su exposición, tomar sólo una rama o parte del problema, ya que el relato oficial abordaría totalmente el asunto. Nuestro análisis corresponde pues, exclusivamente, a las pielonefritis obstructivas o urinarias, a las cuales Bell atribuye la mayor importancia como que las proporciona de 12 a 1 en el orden de frecuencia en relación con las pielonefritis hematógenas o descendentes.

Para nuestro análisis elegimos un conjunto de 150 observaciones de piurias erinicas, tanto de la clientela hospitalaria como civil, que fueron sometidas a estudio urológico completo con el objetivo de discriminar la responsabilidad del árbol urinario en la producción, mantención de la cronicidad o recidivancia de este síndrome. No se prejuzgó de antemano que de este estudio fuese a resultar el diagnóstico de pielonefritis. Hemos elegido 150 observaciones de piuria crónica cuyo examen urológico se hizo lo más completo posible, yendo desde el examen de orina especializado hasta la biopsia o histopatología renal, pasando por el estudio radiológico -radiografía renal simple, pielografía descendente, pielografía directa, pineumorrinón-, cateterismo bilateral para estudio funcional $\mathrm{y}$ bacteriológico de ambos riñones por separado y cuando era necesario se practicaron pruebas de suficiencia renal como uremia, densimetría, ccncentración uréica y pruebas de depuración glomerulares y tubulares.

Hemos dejado a un lado toda otra ectesia urinaria infectada producidas por compromisos extrinsecos como tumores, estrecheces traumáticas y la atonía urinaria de tipo neuropático, que no representan esencialmente una lesión anatómica pura del sistema excretor. Así tendremos como resultante un porcentaje de pielonefritis que representa en forma más o menos exacta la frecuencia de esta afección en este rubro etiopatogénico de la obstrucción que es donde el urólogo desempeña sus funciones especializadas en un ciento por ciento.

Además, este conjunto de 150 observaciones de infección urinaria crónica nos ha permitido llegar junto a la pielonefritis al diagnóstico de otras afecciones como la litiasis urinaria infectada, la tuberculo- 
sis urinaria y las infecciones genitales bajas, que, si bien es cierto no caben dentro del capítulo de la pielonefritis pura, pueden producirla como una complicación o significan potencialmente, una causa de pielonefritis.

De lo dicho anteriormente se desprende que nuestra experiencia corresponde al análisis de una entidad que es la mayor causante de pielonefritis como es la obsirucción o ectasia urinaria infectada; que nuestras observaciones no han sido elegidas con el ánimo preconcebido de encontrar en ellas una pielonefritis y que sí del examen clinico, de orina, pielografía, endoscopía, cateterismo y estudio histológico resulta. posible tabularla como una pielonefritis, ella representará un porcentaje real dentro de esta parte del problema.

Sintetizando el resultado de nuestra experiencia se han confeccionado los siguientes cuadros en que se destaca que los dolores abdominales solos o acompañados a la piuria representan un alto porcentaje como motivo de consulta.

\section{CUADRO I}

"Sintomas acompañantes de la plurla en los 150 casos".

1. Pluria crónlca o tecidivate:

a) Con bacteriuria

b) Sin térmenes (amicroblara)

80

150

a) Lumbar

b) Abdominal

3. Tuaor abdominal.

4. Hematuria.

5. DIsuria.

Cistitis, dolor miccional, poliagluria.

retención orina $g$ seudo incontinencia

B. Hipertension

7. Ragultismo

8. Uremta

9. Hipertermia pespertina

\section{CUADRO II}

"gintoma monitor motivo de consulta obtenido por la anamnesis",

1. Plurla crónlç o recidivante

100

2. Disuria:

Cistitis.

Dolor micional.

Poliaquirta.

Retención orisas.

Seudo incontinenc1s.

3. Hematuria

4. Dolor abdominal

5. Tumor abdorninal

6. Hlpertemla vespertina

7. Uremia

B. Hipertension

9. Raquatismo

$\mathrm{Si}$ bien es cierto que la piuria estuvo constante siempre en los 150 casos, hubo otros sintomas que a veces motivaron la consulta al urólogo y partiendo de allí el estudio nos permitió establecer el diagnóstico definitivo.

\section{CUADRo IU}

"Lesiones encontradas con el estudfo urológlco"

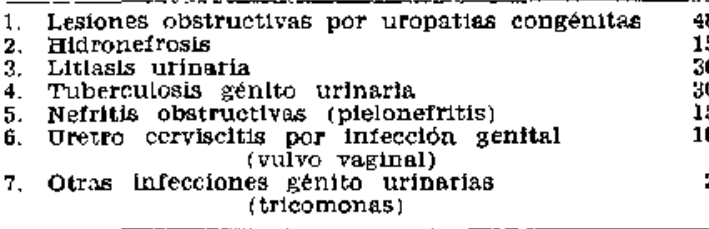

Sin mayor explicación ya que demuestra la cantidad de afecciones encontradas en este estudio.

\section{CCADRO IV}

"Cuadro de porcentajes de las diferemtes afecciones por uropatias obstructivas".

\begin{tabular}{|c|c|c|}
\hline & Ne & $\not z$ \\
\hline $\begin{array}{l}\text { 1. Malformaciones congenitas: } \\
\text { (Uretro vésico, uretero piélleas) } \\
\text { 2. Hidronefrosls } \\
\text { 3. Ultiasis } \\
\text { 4. Tuberculosis } \\
\text { 5. Plelonefrtis } \\
\text { a) Totales: 11tiasis - TBo y plelo = } 75 \\
\text { b) puras por obstrucción } \\
\text { 6. Otras inrecciones }\end{array}$ & $\begin{array}{l}48 \\
15 \\
30 \\
30 \\
15\end{array}$ & $\begin{array}{l}32 \% \\
10 \% \\
20 \% \\
20 \% \\
10 \%\end{array}$ \\
\hline
\end{tabular}

Este cuadro merece una explicación por la incursión de la tbc. en este estudio, tratándose de una entidad especifica pero, para algunos autores, es la afección más pielonefrizante, por asi decirlo. Deberíamos, en realidad, incluir en él, únicamente, a la litiasis e hidronefrosis, que producen pielonefritis por obstrucción.

Antes de entrar al resumen deseamos presentar algunas observaciones de las estudiadas por nosotros, las más características.

\section{OBS. CL. N $I-$ L. M.}

Niño de 9 años con una hidronefrosis izquierda de entidad que suffe un traumatismo sobre dicho flanco $y$ tiene una hematuria.

Su estudio revela una gran hidronefrosis del riñón ixpuierdo y una estrechez ureteral derecha baja, yuxta pílica. que produce un hidrouteter y borramiento papilar del polo superior. Como existen descargas dc colibacilos en Ja orina y piuria, aún después de la nefrectomia izquierda. debemos suponer que ya cxistía un compromiso del parénquima producido por una 

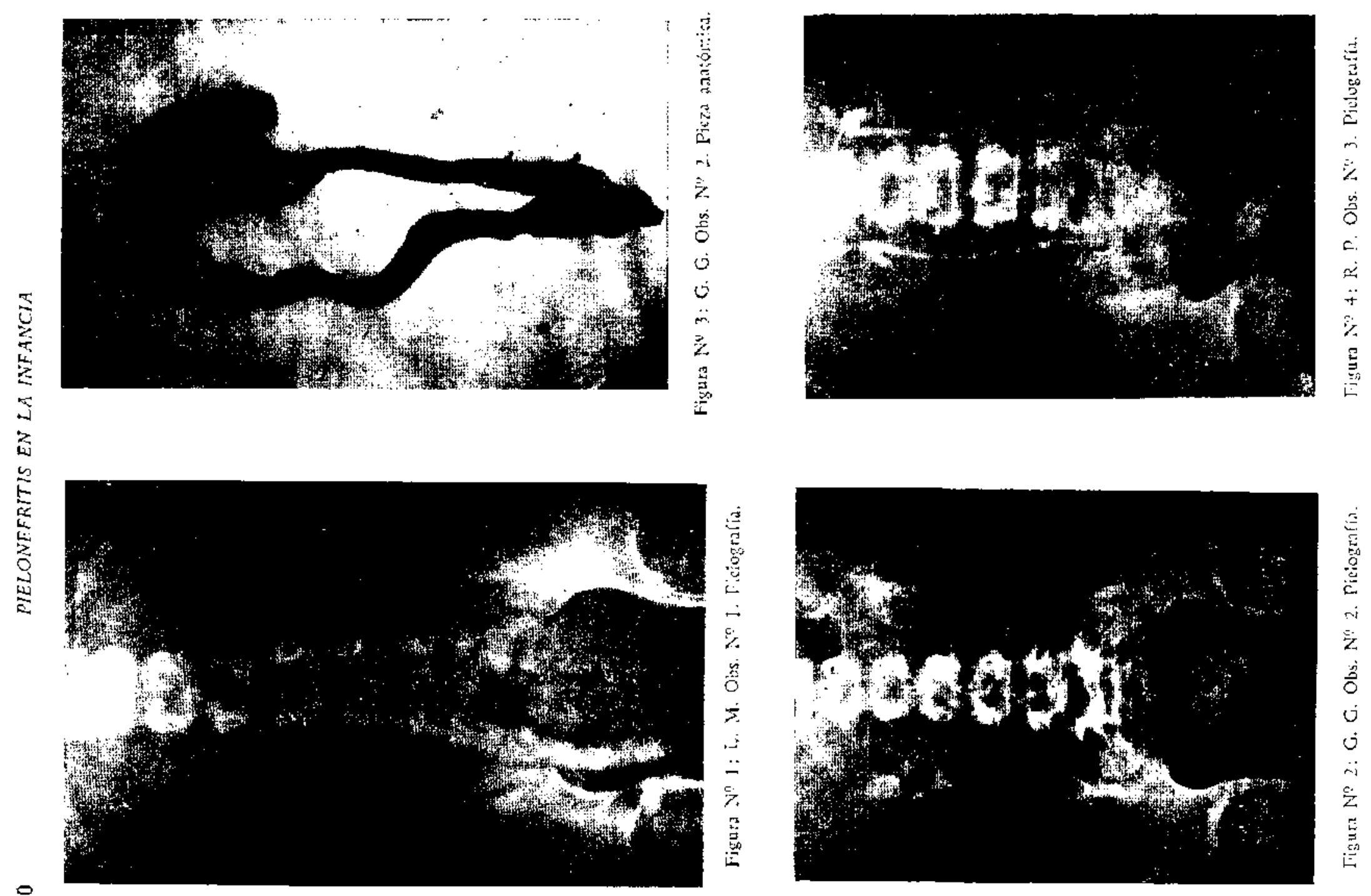

옹

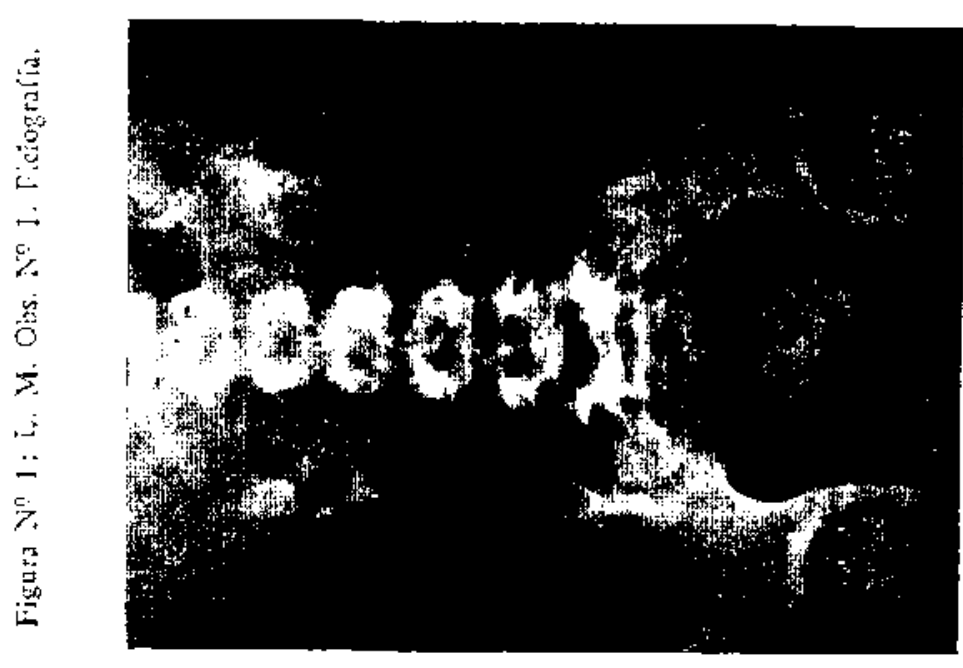

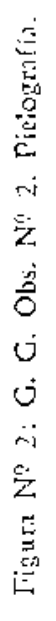




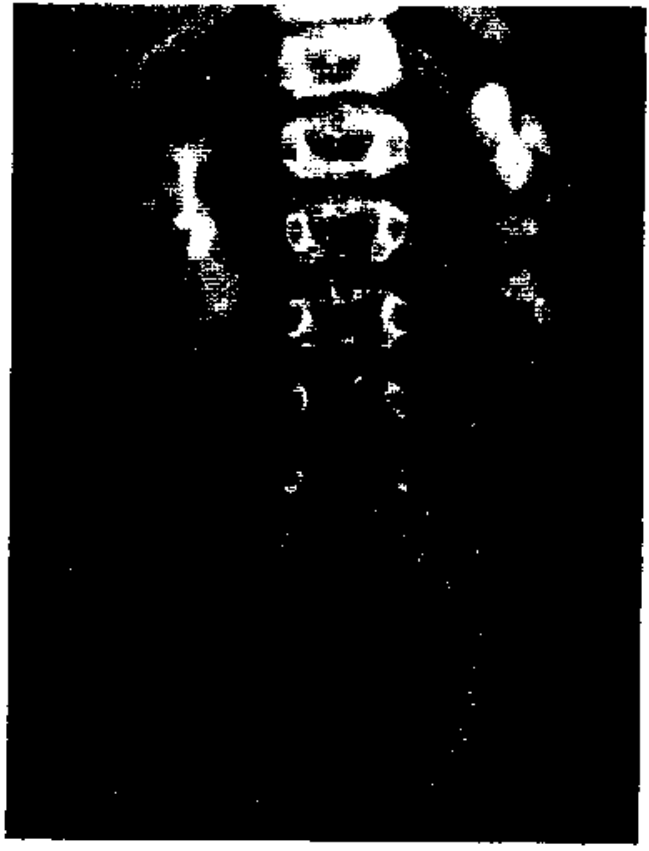

Figne N" 5: A. C. Obs. No 4. Pielografia.

ir.lcción ascondente o retrógrada por la ectosia debida d la estrechez ureteral. Se practica ura segunda interveación sobre el uréter derecho con lo cual las moles. tiàr pasan durante un año y madio y cl vaciamiento se rcilza nejot. Se trata de un caso tipico de pielonetritis acidedere (ligura $N$ ' 1 ).

\section{CBS. CI. N $\mathrm{N}^{\mathrm{P}} 2-\mathrm{G} . \mathrm{G}$.}

Nitis de 7 años con piuria crónica recidivante a colibacilos. cuyo estudio pielografico descendente $y$ diriso reveló una malformatión urológica bilateral: Filvir dobles a cada lado y una pielonefritis intensa detache del riñon superior. Se interviune con miras a practicas heminefrectomia deredsa, pero el acto opera. Lcrio reveló lesiones incensas an ambos suctores de este riñón doble con hidrouriet por lo cual se practica nefrouretetetomia total y el examen y la piezat anató $n$ ica demustin intensas lesiones de pielonefritis $y$ piotrilosis (Figurus $N^{\circ} 2 y^{3}$ )

\section{OBS. C.I. N $N^{\prime}-\mathrm{R} . \mathrm{P}$.}

Corresponde a un nin̆o de 12 años con un riñón bipopisico bialeral que hasta csta colad se ha defandito po: asi deciro. con csisu ćrganos de escaso valar funcions' pero que uns rez agregada la infec. cions. se produce un cuadro de piclonetritis que to lleva facilmence a la insuficiencia tenal. Obsérvese en la pielografia el borramiento papilar bilateral. (Figura No 4 i.

OBS. CI. N $\mathrm{N}^{4}-\mathrm{A} . \mathrm{C}$.

Niño de 10 años cuyo examen fisico tevela un tu. ric: de ambos l!ancos. motivo de su consulta y cupo cxamen pielogrấtón nos demuestrz un riñón en herradura hidronelfótico. Como no existe inlecsión, pero si intensa altiracićn papilar y calicilar, debemos pensar que falta cinitamenef la invas'on de fórmenes para que se prodazan lesiones graves de piclonefritis y el

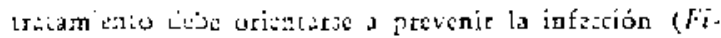
gura $N^{\prime \prime} 5$,

Así poidríamoz seguir preseniando rariados ejomplos de csta afección en casos de piura por anomalias, etc., litiasis y aún por iniecciones genitales que alargarian inut!lnemite este aporte.

\section{RESUMEN}

Potcmus texmina: diciendo que nuestra experiencia derivada del estudio de 150 casos de piuria crónica o recidivante en el niño $y$ en relación cuusal con otras afcoicres, ospecialmente con la pielonefritis, nos permite sacar las siguientes deducciones que nos atrevemos denominar conclusiones por las caracteristicas ya expuestas en nuestra investigación.

10 Pensamos que se hacen más diagnósticos de pielonefritis que los verdaderos for razones de interpretaciones exclusivamente clínicas que hacen necesario pensar en esta afección para que no dejemos de diagnosticarla.

2. Que el diagnóstico de pielonefritis es dificil y que para llegar a él se necesita poner en juexo todos aquellos elementos ya mencionados, desde la clínica, el examen urológico especializado, hasta la hispatología para establecer fehacientemente aue estamos en presencia de esta afección por lo que ello importa en el pronóstieo $y$ tratamiento.

$3^{\circ}$ Que nos parece recomendable considerar a toda piuria por uropatía obstructiva, como una pielonefritis potencial que debe controlarze en forma periódica $y$ permanente.

4. Que en el estudio y en el tratamiento de esta afección es donde se aprecia, más que nunca, la efectividad del trabajo médico en equipos.

5 ? Que dada la frecuencia de las piurias crónicas en el niño y su relación con estas uropatías, lo que sumado a lo que significan como problema médico, las nefropafías médicas en general, deberíamos asignarles una categoria preventiva $y$ asistencial similar a la que se ha hecho con las tuberculosis, cáncer $\mathrm{y}$ cardiopatías. 


\section{BIBLIOGRAFÍA}

1.-ARMas cruz, R. y cols. - "Revista Médica de Ch1le". 1956

2.-JLMENEZ DLAZ. - "Tratado de Medicina Interns". 3.-BELL. - "Enfermedades renbles". 1948.

4-CODVELAIRE. - "EH urologo ante las neIritis as. cendentes". Journ, d'Urologie. T. 60 , No 11,1954 OBERLING. - "Las nefritis crontcas ascendentes. Anatomia Patológica".

6.-FONTAINE, B. - "Fitudio clínico de las nefritis ascendetes". Monografias de le Soc. de Patologia Renal. 1955.

7.-CAMPBELL, M. - "Tratado de urologla infantil". 1850 .

\section{DISCUSION}

Dr. Atriagada: De un análisis del material de infecciones urinarias en el Servicio de Pediatría del Hospital Clinico Regional de Concepción, deseamos destacar los siguientes bechos que nos parecen de interés:

I) Se ha comprobado la presencia de piurias prolongadxs con urocultivos positivos en cuadros catalogados como glomérulonefritis aguda, glomérulonefritis crónica y sindrome nefrósico.

2) Por falta de suficiente control posterior, no podemos en este momento establecer si aliguno de los casos referidos evolucionara hacia el riñón reraído sccundario.

3) En un aumeroso material de glomérulonefritis aguda sin piuria, obtuvimos urocultivos positivos.

4) En los pocos cisos en que se practicó estudio histopatotógico de los riñones de niños fallecidos con diagaóstico de glométulonefritis crónica y piuría. se pudo comprobar alteraciones asociadas de glomírulonefritis tipica de forma crónica con thanifestaciones de antigua pielonefritis. En ottos casos con historia de hipertensión arterial, insuficiencia tenal y cardíaca, con - sin antecedentes de piuria previa, el estudio de la biopsia renal o de! material necrópsico. mostró cicarrices pielonefriticas y alteraciones histológicas correspondientes a la misma etiología.

5) Similares observaciones ha acumulado el Servicio de Medicina de adulcos del Höpital Clinico Regional de Concepción, en el cual se prepara una investigación experimental para estlarecer diversos hechos sobre el mismo problema.

6) Las relaciones entre infección urinatia y gefritis no. nos parceen de clata interptetación a la luz de nuestra experiencia. Igroramos si se trata de dos afecciones concomilantes de evolución independiente entre si. o si alguna de ellas inicia el cuadro creando condiciones favorables para el desarrollo de la otra o, finalmente, si el cuadro corresponde a una sola entidad clinici como es lo más probable. 